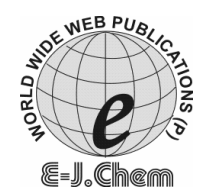

http://www.e-journals.net
ISSN: 0973-4945; CODEN ECJHAO

E-Journal of Chemistry 2009, 6(4), 965-974

\title{
Synthesis, Characterizations and Investigation of Electrochemical Behaviours of 4-[(2-Hydroxyphenylimino)methyl]benzene-1,3-diol
}

\author{
AYSEN D. MULAZIMOGLU, IBRAHIM ENDER MULAZIMOGLU* \\ and BEDRETTIN MERCIMEK
}

\author{
Selcuk University, Department of Chemistry, 42099, Konya, Turkey \\ mulazimoglu@gmail.com
}

Received 16 July 2008; Accepted 20 September 2008

\begin{abstract}
This Schiff base ligand, 4-[(2-hydroxyphenylimino) methyl]benzene-1,3-diol (HIBD) was synthesized by reaction of 2aminophenol and 2,4-dihydroxybenzaldehyde. The ligand was characterized by elemental analysis, FT-IR and ${ }^{1} \mathrm{H}-\mathrm{NMR}$. Electrochemical behaviors were investigated on the glassy carbon electrode (GC) surface with cyclic voltammetry $(\mathrm{CV})$. The modification of HIBD on the GC was performed in $+0.3 \mathrm{~V}$ and $+2,8 \mathrm{~V}$ potential range using $100 \mathrm{mV} \mathrm{s}^{-1}$ scanning rate having 5 cycle. For the characterization of the modified surfaces $1 \mathrm{mM}$ ferrocene redox probe in $0,1 \mathrm{M}$ tetrabutylammonium tetrafluoroborate (TBATFB) and $1 \mathrm{mM}$ ferricyanide redox probe in $0.1 \mathrm{M} \mathrm{H}_{2} \mathrm{SO}_{4}$ were used.
\end{abstract}

Keywords: Schiff base, Cyclic voltammetry, Synthesis, Surface modification.

\section{Introduction}

Electrochemical biosensors combine the specificity of the biological species and the analytical power of electrochemical techniques. Schiff bases play an important role in bioinorganic chemistry as they exhibit remarkable biological activity. Schiff base metal complexes have been recognized as powerful catalysts in a great number of chemical reactions such as, electrochemical reduction of alkyl halides in aprotic solvents, oxygenation of indols, phenols, flavones, and others. Schiff bases form an interesting class of chelating ligands that has enjoyed popular use in the coordination chemistry of transition, inner-transition and main group elements ${ }^{1-5}$. Schiff base macrocyclic ligands based on 
thiosemicarbazones and their complexes have received considerable attention since, because of their pharmacological properties, they have numerous applications, for example as antibacterial and anticancer agents ${ }^{6-8}$. They can yield mono- or polynuclear complexes, some of which are biologically relevant ${ }^{9-12}$; for example, some copper complexes can serve as models for enzymes such as galactose oxidase and may be used as effective oxidant and redox catalysts ${ }^{13,14}$. The Schiff base obtained has been versatile in forming a series of complexes with $\mathrm{Mn}$ (II), $\mathrm{Fe}(\mathrm{II}), \mathrm{Co}(\mathrm{II}), \mathrm{Ni}(\mathrm{II}), \mathrm{Cu}$ (II) and $\mathrm{Zn}$ (II) ions under well defined conditions and these complexes have been investigated with particular reference to the structural aspects of the ligand moiety in the metal complexes. Besides the structural diversities and bonding interactions, bioisosteric relationship of thiophene to benzene has led to several structures of drug analogs in which benzene rings have been replaced by thiophene rings and the vivid applications of thiophene derivatives as important therapeutic agents have been well documented in literature ${ }^{15,16}$.

Several researches have proposed that the redox potential in macrocyclic and Schiff-base complexes is directly related to many of the biologically relevant chemical characteristics of the entire complex, e.g. dioxygen binding ability and nucleophilicity ${ }^{17}$. Thus, there has been a strong interest in determining thermodynamically meaningful redox potentials of copper Schiff-base complexes and in understanding the relationship between these potentials and the detailed structure of the Schiff-base ligand ${ }^{18}$. Numerous electrochemical studies have been made for a fairly large number of acyclic and macrocyclic copper(II) complexes derived from Schiff-bases. These investigations revealed that the redox properties of copper(II) complexes are markedly influenced by structural and electronic factors ${ }^{19,20}$. Transition metal Schiff-base complexes are interesting due to their capability to form adducts with dioxygen and may thus catalyse dioxygen reduction. The transition metal ions in the complexes form adduct with dioxygen via charge transfer. These complexes would thus be expected to show catalytic effects ${ }^{21}$.

Chemically modified electrodes have been the subject of considerable attention since their inception about 27 years ago ${ }^{22}$. With the deliberate immobilization of a modifier agent onto an electrode surface, it is hoped that the physicochemical properties of the modifier will be transferred to the electrode surface. This modification seeks to dictate and control the behavior of the electrode/solution interface ${ }^{23,24}$.

\section{Experimental}

\section{Reagents and chemicals}

All chemicals were of analytical-reagent grade from Fluka and Sigma-Aldrich and were used directly without further purification. All solutions and supporting electrolyte were used to prepare with $0,1 \mathrm{M}$ TBATFB in acetonitrile. In all experiments, the solutions and the electrodes were kept in acetonitrile when they were not in use. All the experiment solutions were prepared at $1 \mathrm{mM}$ concentration used in surface modification. Solutions were thoroughly deoxygenated by purging with purified argon gas $(99.99 \%)$ for $10 \mathrm{~min}$ prior to the electrochemical experiments. Argon blanket was maintained over the solutions to supply an inert atmosphere during voltammetric measurements. All electrochemical experiments were performed at room temperature $\left(25 \pm 1{ }^{\circ} \mathrm{C}\right)$. 


\section{Electrodes and apparatus}

The IR spectra of the ligand was recorded with a Perkin Elmer model 1605 FT-IR spectrophotometer instrument in $\mathrm{KBr}$ pellets. Elemental analysis was performed with Leco 932. ${ }^{1} \mathrm{H}$ and ${ }^{13} \mathrm{C}$ NMR spectra were recorded on a Bruker DPX-400 MHz Digital FT-NMR spectrometer in DMSO- $\mathrm{d}_{6}$. All electrochemical measurements were performed with an E2P Electrochemical Analyzer w/BAS electrochemical workstation with C3 cell stands (Bioanalytical Systems, Inc., BAS in USA). Electrochemical experiments were carried out using a conventional three-electrode system. A three-electrode cell was employed incorporating a glassy carbon electrode (BAS Model MF-2012, $0.071 \mathrm{~cm}^{2}$ diameter) as working electrode, $\mathrm{Ag} / \mathrm{Ag}^{+}(0,01 \mathrm{M}$ $\mathrm{AgNO}_{3}$ in $0,1 \mathrm{M}$ TBATFB) (BAS Model MF-2042) for non-aqueous medium and $\mathrm{Ag} / \mathrm{AgCl} / 3$ $\mathrm{M} \mathrm{KCl}$ (BAS Model MF-2063) for aqueous medium as reference electrodes and a platinum wire (BAS Model MW-1032) as auxiliary electrode. Reference electrodes calibrated to the $E_{1 / 2}$ of 1 $\mathrm{mM}$ ferrocene in $0.1 \mathrm{M}$ TBATFB and $1 \mathrm{mM}$ ferricyanide in $0.1 \mathrm{M} \mathrm{H}_{2} \mathrm{SO}_{4}$.

\section{Synthesis of Schiff base}

The ligand was prepared by drop wise addition of a solution of the 2-aminophenol $(0.1582 \mathrm{~g}$, $3 \mathrm{mmol})$ in $10 \mathrm{~mL}$ ethanol to a stirred solution of 2,4-dihydroxybenzaldehyde $(0,4144 \mathrm{~g}, 3$ $\mathrm{mmol}$ ) in $10 \mathrm{~mL}$ ethanol. After the addition was completed, the mixture was stirred at room temperature for $7 \mathrm{~h}$. It was washed with ethanol and subsequently dried over anhydrous $\mathrm{CaCl}_{2}$ in a desiccators (Figure 1).<smiles>Cc1cccc(/N=C/c2ccc(O)cc2O)c1O</smiles>

Figure 1. Synthesis of 4-[(2-hydroxyphenylimino)methyl]benzene-1,3-diol (HIBD).

\section{Elemental Analysis}

Elemental anaysis: Found: $\mathrm{C}, 68,10 ; \mathrm{H}, 4,80 ; \mathrm{N}, 6,12 \%$. Calc. for $\mathrm{C}_{13} \mathrm{H}_{11} \mathrm{NO}_{3}: \mathrm{C}, 68,11 ; \mathrm{H}$, 4,$84 ; \mathrm{N}, 6,11 \%$.

\section{Infrared spectra}

Characteristic IR band $\left(\mathrm{KBr}, \mathrm{v}, \mathrm{cm}^{-1}\right)$ of Schiff base showed at $1640(\mathrm{C}=\mathrm{N})$.

\section{${ }^{1} H$-NMR spectra}

The ${ }^{1} \mathrm{H}$ NMR spectra in DMSO- $\mathrm{d}_{6}$ of the Schiff base showed signals at $10.16(\mathrm{~s}, 1 \mathrm{H}), 9.69$ (s, 2H) Ar-OH; $8.76(\mathrm{~s}, 1 \mathrm{H}) \mathrm{HC}=\mathrm{N} ; 7.35(\mathrm{~d}, 1 \mathrm{H}, \mathrm{J}=8.5), 7.28(\mathrm{dd}, 1 \mathrm{H}, \mathrm{J}=1.5,7.9), 7.05$ (t, $1 \mathrm{H}, \mathrm{J}=7.7), 6.91(\mathrm{~d}, 1 \mathrm{H}, \mathrm{J}=6.9), 6.83(\mathrm{t}, 1 \mathrm{H}, \mathrm{J}=7.6), 6.32(\mathrm{dd}, 1 \mathrm{H}, \mathrm{J}=2.3,8.5), 6.21(\mathrm{~d}$, $1 \mathrm{H}, \mathrm{J}=2.2) \mathrm{Ar}-\mathrm{H}$ ppm

\section{Preparation of modified electrode}

Prior to each experiment, the glassy carbon surface was polished to a mirror-like surface with 0.3 and $0.05 \mu \mathrm{m}$ of alumina slurry on a polishing cloth with ultrapure water and then sonicated in an ultrasonic bath for about $5 \mathrm{~min}$ to eliminate any trace of polishing paste from the surface in water/acetonitrile-ipa/water for $5 \mathrm{~min}$. In order to prepare a modified GC surface with HIBD, the electrode was immersed in a $1 \mathrm{mM}$ solution of the HIBD in nonaqueous $0,1 \mathrm{M}$ TBATFB (in acetonitrile) solution and the potential was cycled between +0.3 and $+2.8 \mathrm{~V}$ (at $100 \mathrm{mV} / \mathrm{s}$ ). 


\section{Results and Discussion}

Investigation of electrochemical behaviors of HIBD modified GC

The electrochemical behavior of HIBD on GC surface was investigated using CV technique. $1 \mathrm{mM}$ HIBD (in $0.1 \mathrm{M}$ TBATFB) was prepared and used in the modification process. The modification of the molecule to the surface was performed in the $+0.3 \mathrm{~V}$ and $+2,8 \mathrm{~V}$ potential range using $0.1 \mathrm{~V} \mathrm{~s}^{-1}$ scanning rate with 5 cycles (Figure 2). Three different irreversible oxidation peaks were observed at 932, 1444 and $2327 \mathrm{mV}$.

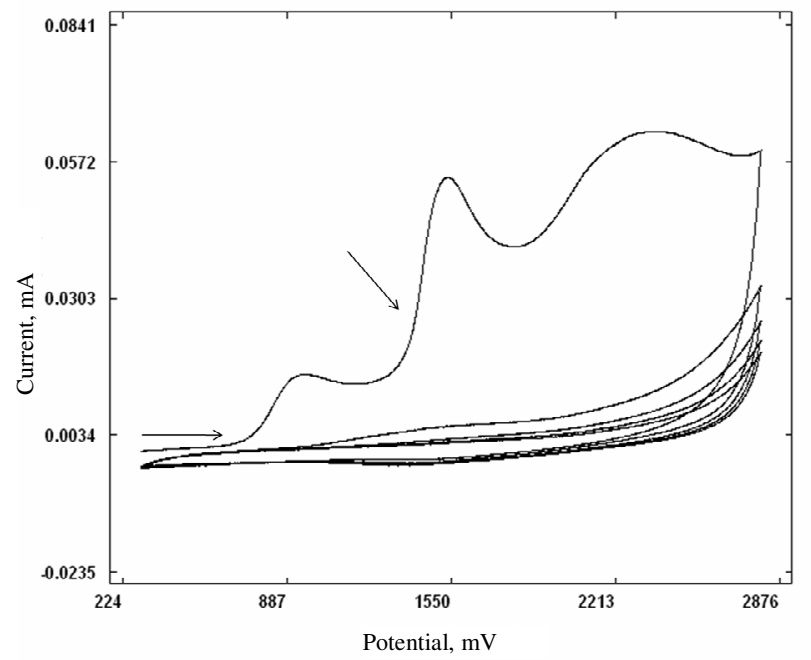

Figure 2. Cyclic voltammogram of HIBD in the presence of $0.1 \mathrm{M}$ TBATFB in acetonitrile, $+0.3 \mathrm{~V}$ and $+2.8 \mathrm{~V}$ potential range using $100 \mathrm{mV} \mathrm{s}^{-1}$ with 5 cycle.

The disappearance of these peaks after the second cycle proves the binding of the molecule to GC surface. Overlaying the bare GC and modified GC surface using ferrocene and ferricyanide redox probe, also voltammograms the modified surface indicates that the molecule bind to the GC surface (Figure 3). In other words, although the GC surface allows electron transfer, the modified surface does not allow electron transfer.

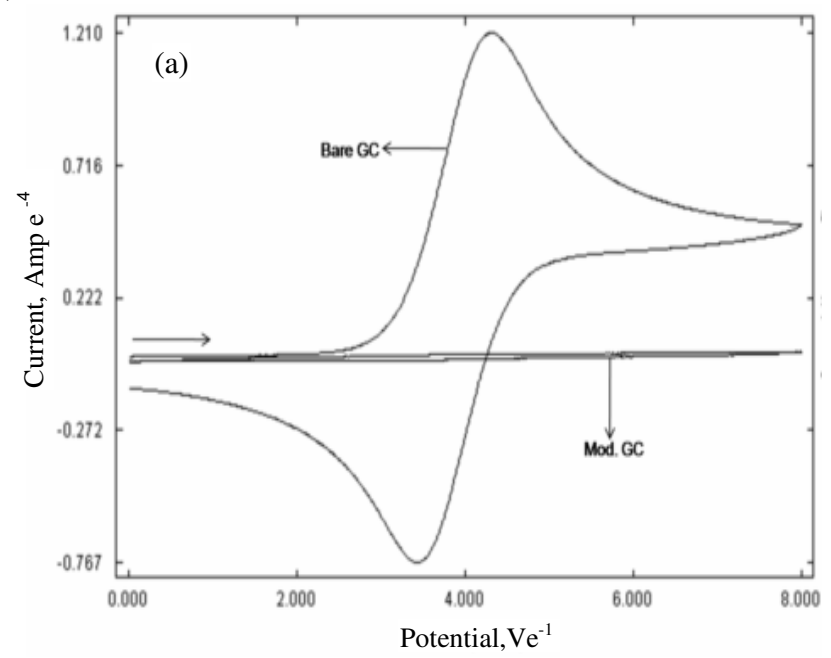




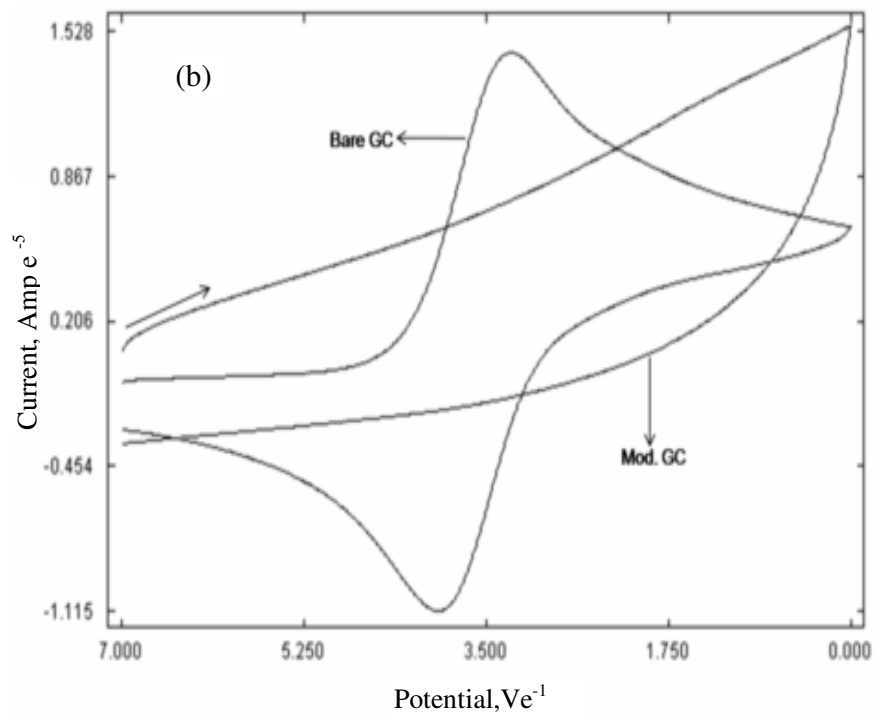

Figure 3. Overlaying surface voltammograms for HIBD full modification (a) the bare GC and HIBD modified GC with ferrocene and than (b) the bare GC and HIBD modified GC with ferricyanide

To understand the binding peak among the three, the modification was tried to be performed by reversing the cycle at end of the second and the first peak. This process corresponds to $+0.3 \mathrm{~V}$ and $+1.2 \mathrm{~V}$ and $+0.3 \mathrm{~V}$ and $+1.8 \mathrm{~V}$ potential range for the second and first peak respectively (Figure $4 \& 6$ ) and surface voltammograms (Figure 5, $7 \& 8$ ).

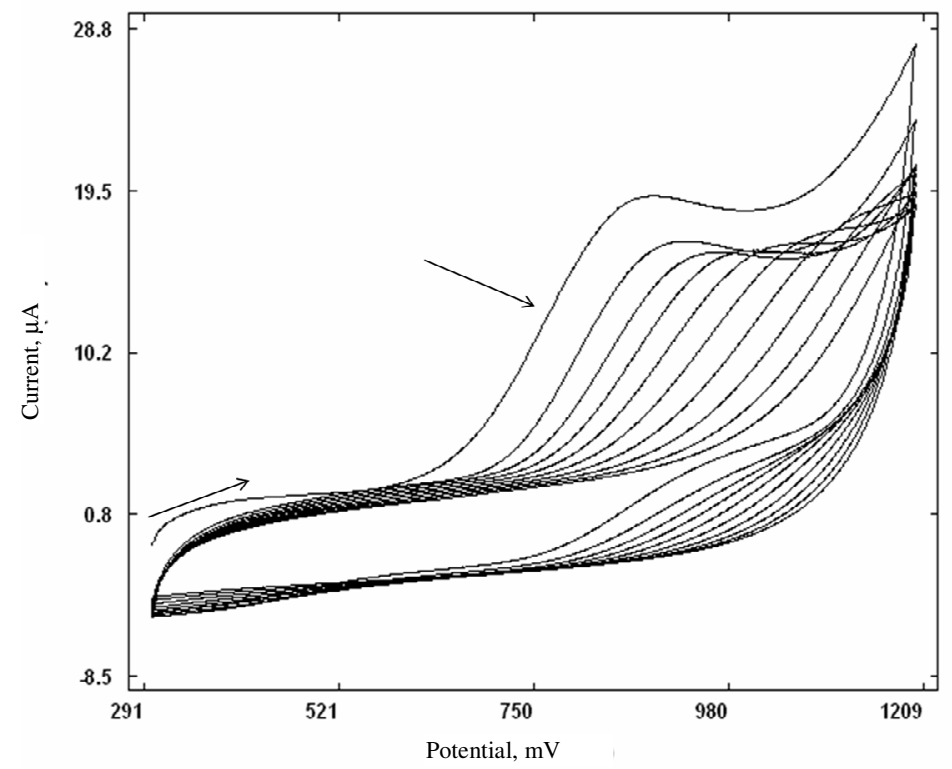

Figure 4. Cyclic voltammogram of HIBD in the presence of $0.1 \mathrm{M}$ TBATFB in acetonitrile, $+0.3 \mathrm{~V}$ and $+1.2 \mathrm{~V}$ potential range using $100 \mathrm{mV} \mathrm{s}^{-1}$ with 10 cycle. 

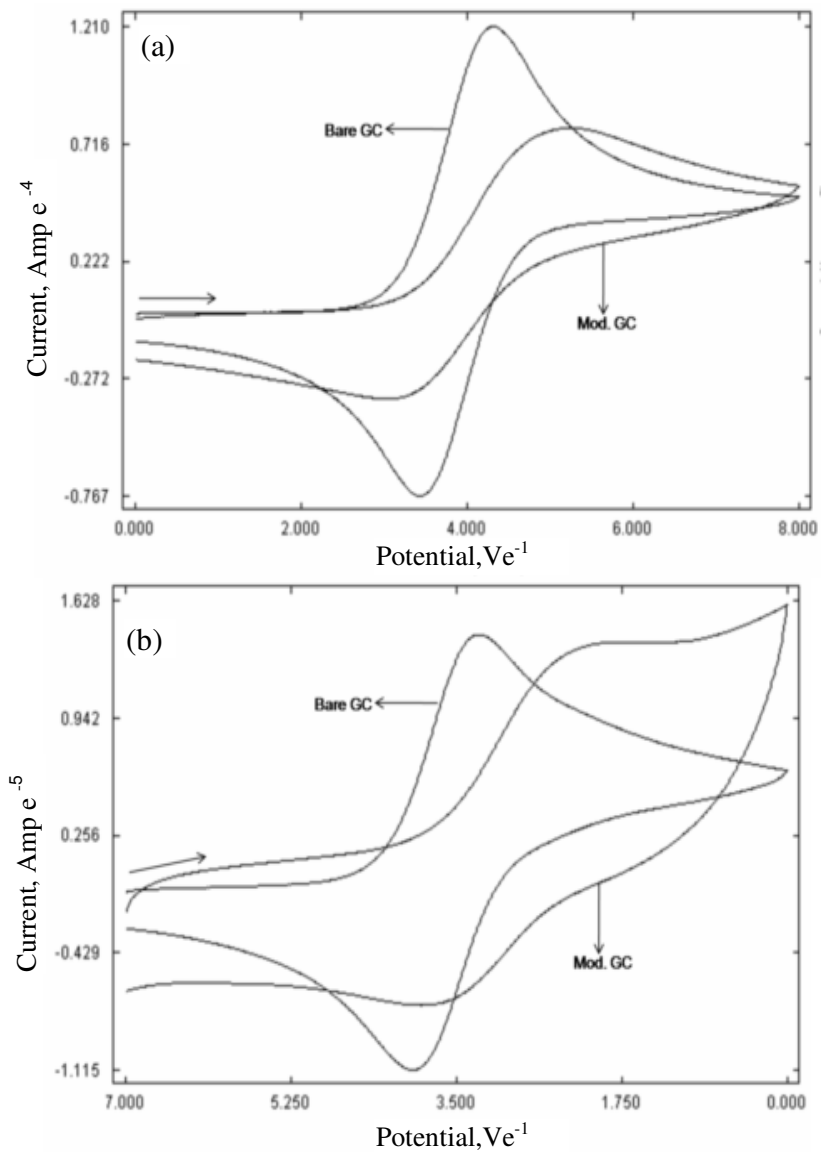

Figure 5. Overlaying surface voltammograms for first peak (a) the bare GC and HIBD modified GC with ferrocene and than (b) the bare GC and HIBD modified GC with ferricyanide

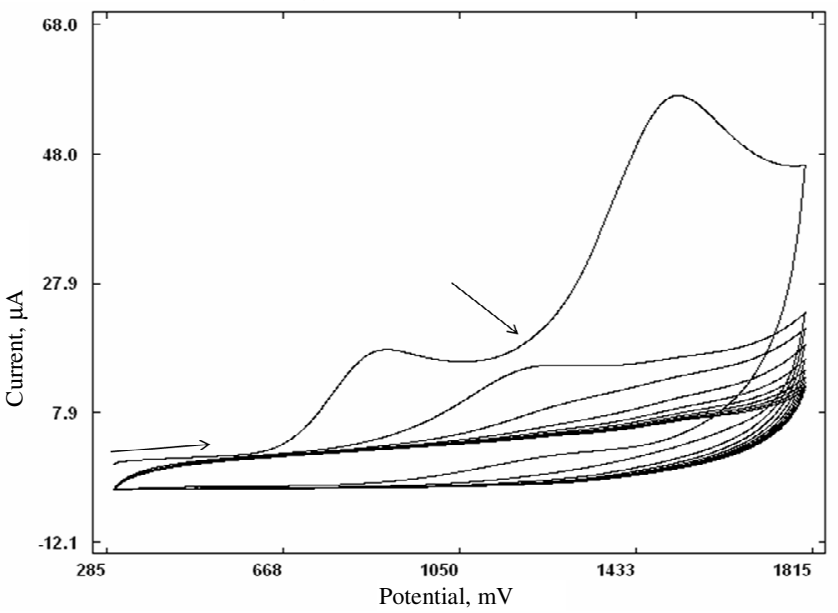

Figure 6. Cyclic voltammogram of HIBD in the presence of $0.1 \mathrm{M}$ TBATFB in acetonitrile, $+0.3 \mathrm{~V}$ and $+1.8 \mathrm{~V}$ potential range using $100 \mathrm{mV} \mathrm{s}^{-1}$ with 10 cycle. 

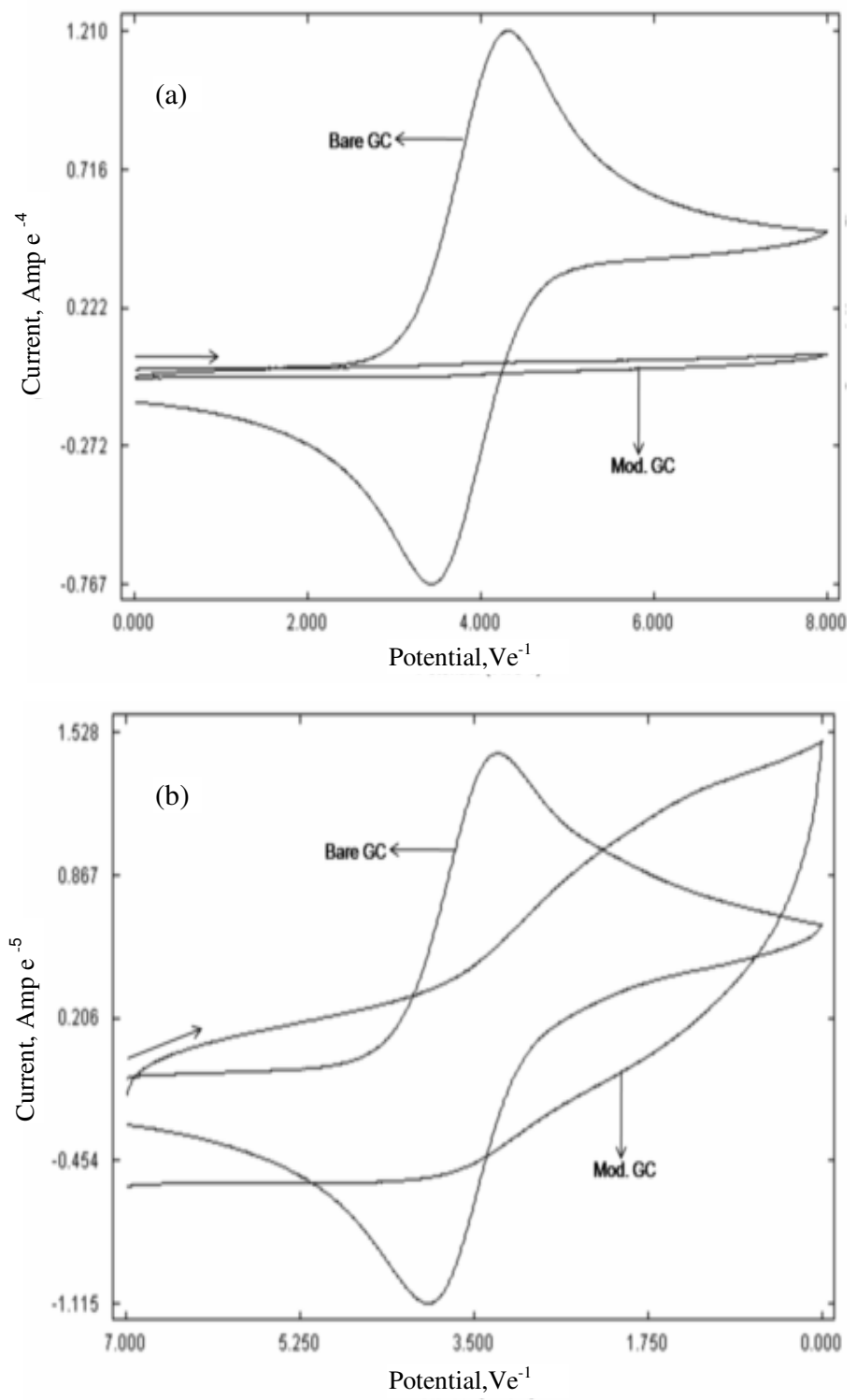

Figure 7. Overlaying surface voltammograms for second peak a) the bare GC and HIBD modified GC with ferrocene and than b) the bare GC and HIBD modified GC with ferricyanide.

In both cases, ferrocene and ferricyanide characteristic voltammograms are shown Figure 8(a) and 8(b). It was found that the third peak belongs to the binding of the molecule to GC surfaces and the other two peaks belong to the oxidation of - $\mathrm{OH}$ groups on phenyl ring.

Reaction mechanism for electrochemical modification of HIBD on GC

As a result, the molecule first oxidized in solution (electrochemical) and than bind to GC surface (chemical) after loosing an electron and a proton from the molecule. The binding took place through $\mathrm{C}-\mathrm{O}$ bonding and the reaction mechanism is shown in Figure 9. 

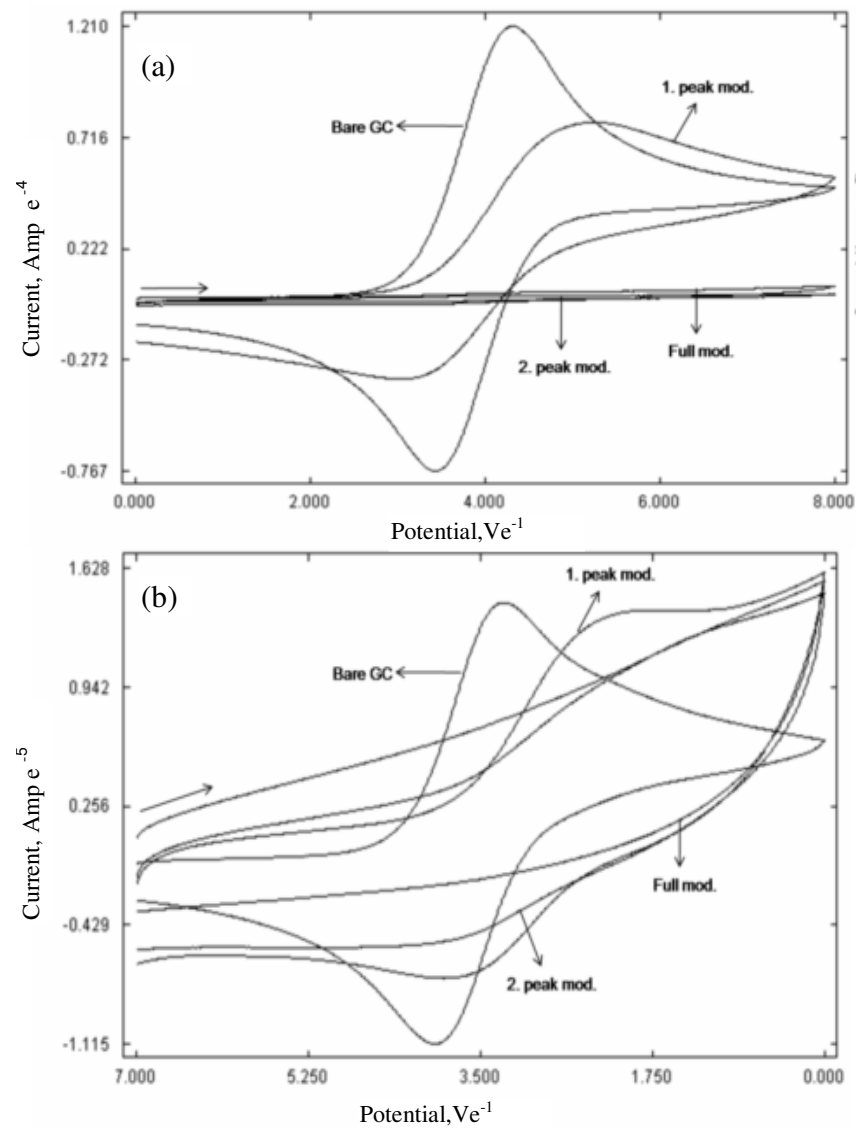

Figure 8. Overlaying surface voltammograms for full peak, first peak and second peak (a) the bare GC and HIBD modified GC with ferrocene and than (b) the bare GC and HIBD modified GC with ferricyanide

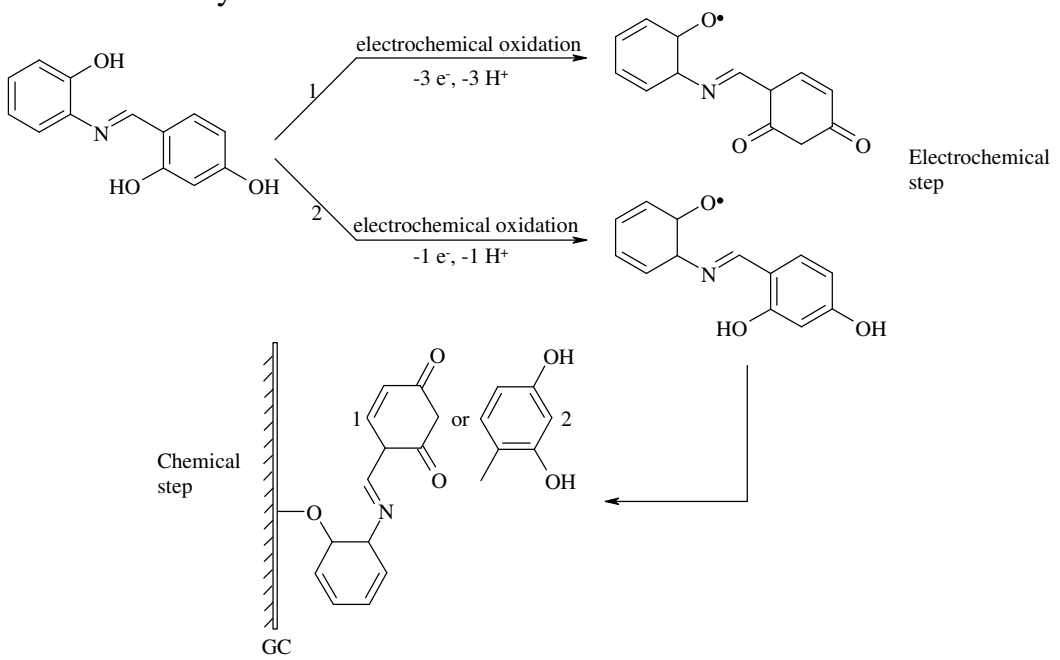

Figure 9. Reaction mechanism for electrochemical oxidation and modification of HIBD on GC. 


\section{Conclusions}

In this research, the behaviour of HIBD was investigated by electrochemically on the glassy carbon electrode surfaces. From the study, HIBD was found to binding through EC (Electrochemical and then Chemical) mechanism. Electrochemically oxidized HIBD at the first step binds to the electrode surface electrochemically at the second step. In the modification process of HIBD on the glassy carbon electrode surfaces, both electrochemical oxidation steps and chemical binding step were clearly determined. Based on the experimental results, a reaction mechanism was proposed and depicted in Scheme 9. The modification voltammograms obtained from cyclic voltammetry modification process, shows that quercetin binded strongly to the electrode surface. This result was supported by cyclic voltammetry surface test in non-aquous medium using ferrocene redox probe and ferricyanide redox probe in aquous medium.

\section{Acknowledgement}

This study was conducted as a part of Ph. D. Thesis of Ayşen Demir Mülazımoğlu. We would like to thank to the Research Foundation of Selçuk University, Konya-TURKEY (BAP-08101026) for financial support of this work.

\section{References}

1. Vigato P A and Tamburini S, Coord Chem Rev., 2004, 248, 1717.

2. Holm R H, Everett Jr G W and Chakravorty A, Prog Inorg Chem., 1966, 7, 83.

3. Calligaris M, Randaccio L, Wilkinson G, Gillard R D and McCleverty J A (Eds.), Comprehensive Coordination Chemistry, Pergamon Press, Oxford, 1987, 2

4. Collinson S R and Fenton D E, Coord Chem Rev., 1996, 148, 19.

5. Garnovski A D and Vasilchenko I S, Russ Chem Rev., 2002, 71, 943.

6. West D X, Liberta E, Padhye S B, Chikate R C, Sonawane P B, Kumbar A S and Yeranda R S, Coord Chem Rev., 1993, 123, 49.

7. West D X, Padhye S B and Sonawane P B, Struct Bonding, 1991, 76, 1.

8. Haiduc Y and Silvestru A, Coord Chem Rev., 1990, 99, 253.

9. Ichiro O E, Busch D and Shull H (Eds.), Bionorganic Chemistry, Allym and Bacon, Boston, MA, 1977.

10. Hay R W, Dilworth J R and Nolan K B, Bioinorganic Chemistry, JAI Press, London, 1991, 1

11. Yam V W W, Pui Y L, Li W P, Lo K K W and Cheung K K, J Chem Soc., Dalton Trans., 1998, 3615.

12. Malachowski M R, Dorsey B T, Parker M J, Adams M E and Kelly R S, Polyhedron, 1998, 17, 1289.

13. Hathaway B J, Wilkinson G, Gillard R and McCleverty J A (Eds.), Comprehensive Coordination Chemistry, Pergamon, Oxford, 1987.

14. Maragerum D W, Owens G D and Sigel H (Ed.), Metal Ions in Biological Systems, Marcel Dekker, New York, 1981.

15. Kellogg R M, Bird C W and Cheeseman G W H (Eds.), Comprehensive Heterocyclic Chemistry, Pergamon Press, Oxford, 1984, 4.

16. Daniel V P, Murukan B, Sindhu Kumari B and Mohanan K, Spectrochimica Acta Part A, 2008, 70, 403.

17. Carter M J, Rillema D P and Basolo F, J Am Chem Soc., 1974, 96, 392.

18. Averill D F and Broman R F, Inorg Chem., 1978, 17, 3389.

19. Patterson G S and Holm R H, Bioinorg Chem., 1975, 4, 257. 
20. Rorabacher D B, Martin M J, Koenigbauer M J, Malik M, Schroeder P R, Eudicott J F, Ochrymowyez L A., Karlin K D and Zubieta J (Eds.), Copper Coordination Chemistry: Biochemical and Inorganic Perspectives, Academic Press, New York, 1983.

21. Elmorsi M A, Gabor M and Barendrecht E, J Appl Electrochem., 1991, 21, 1005.

22. Moses P R, Wier P and Murray R W, Anal Chem., 1975, 47, 1882.

23. Abruna H D, Coord Chem Rev., 1988, 86, 135.

24. Chiericato Jr G, Silva A P S and Guinesi L S, Polyhedron, 2004, 23, 1953.

25. Mülazımoğlu A D, Ph. D. Thesis, "Synthesis of Some Schiff Bases, Investigation of Antibacterial Activities and Electrochemical Behaviors", Selçuk University, Institue of Natural and Applied Sciences, Konya, Turkey, 2008. 


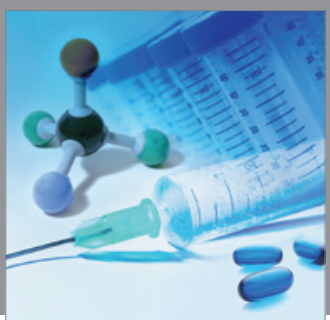

International Journal of

Medicinal Chemistry

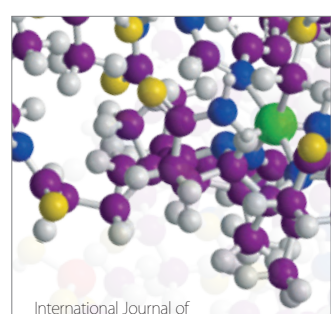

Carbohydrate Chemistry

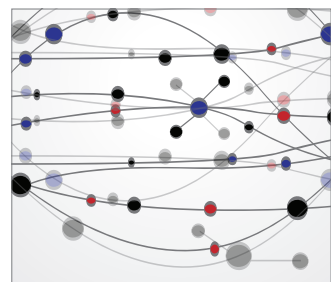

The Scientific World Journal
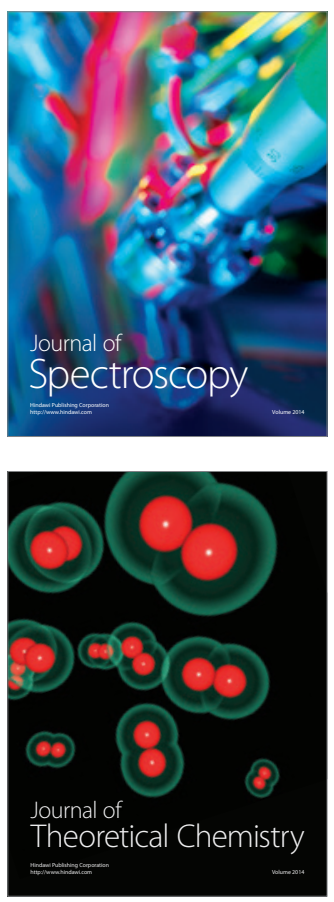
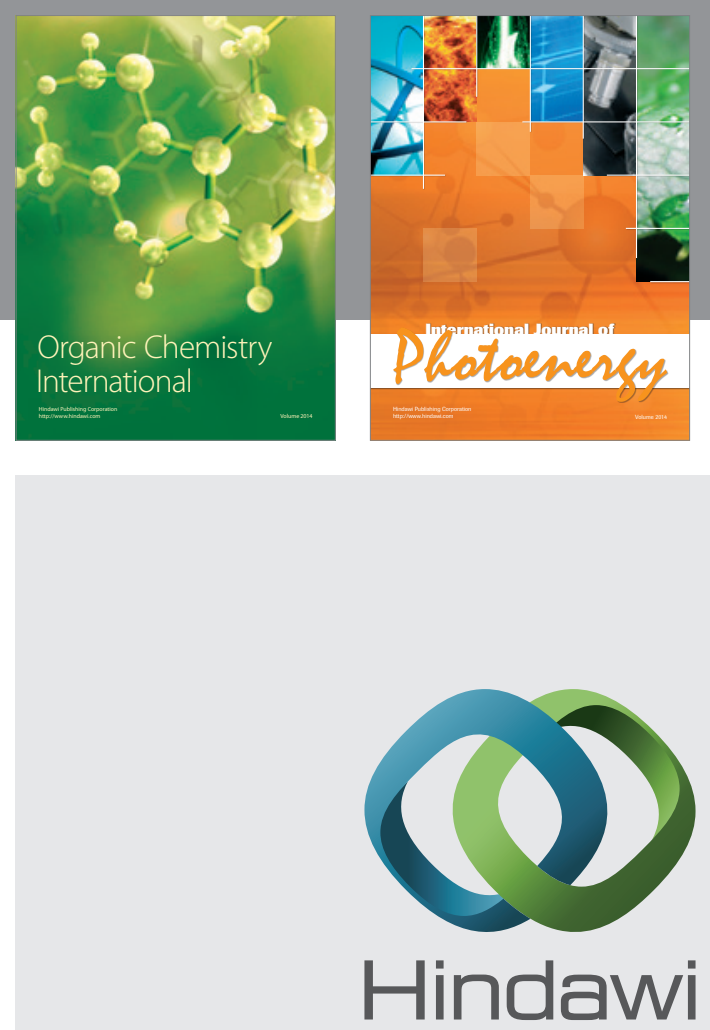

Submit your manuscripts at

http://www.hindawi.com
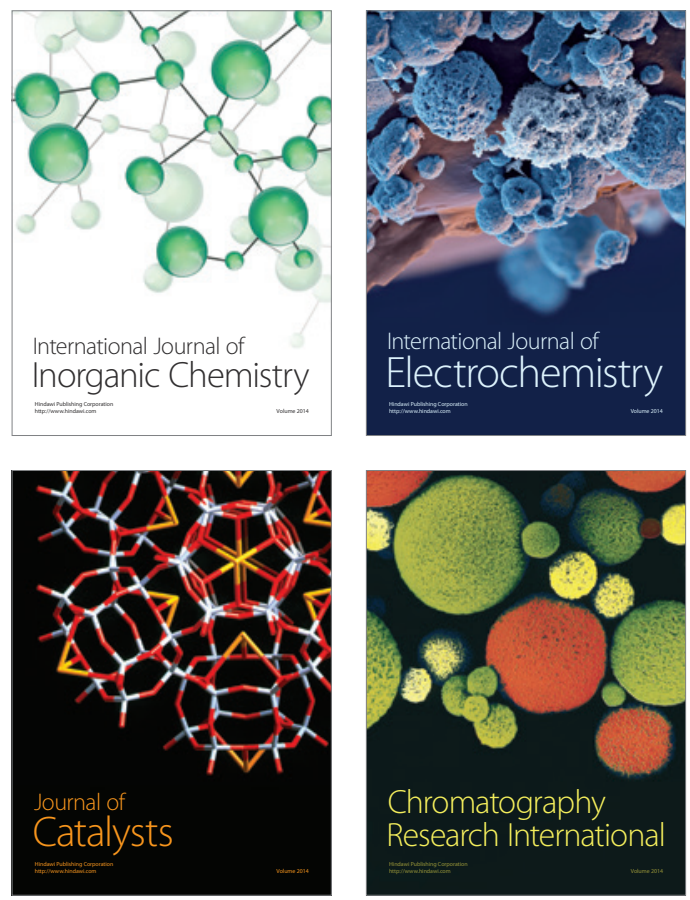
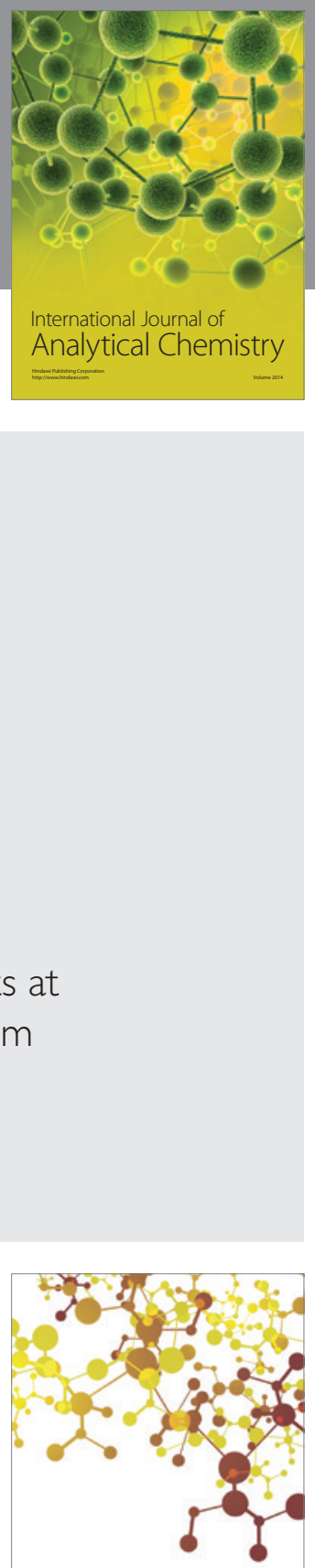

Journal of

Applied Chemistry
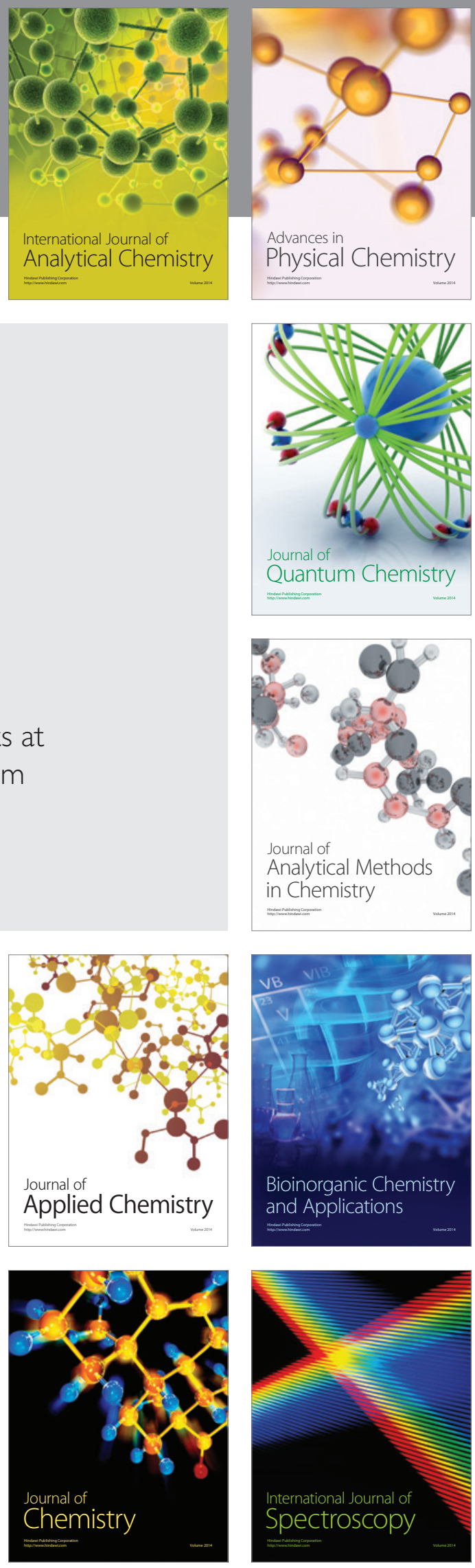